\title{
Self-perpetuating Mechanisms of Immunoglobulin G Aggregation in Rheumatoid Inflammation
}

\author{
J. Lunec, D. R. Blake, S. J. McCleary, S. Brailsford, and P. A. Bacon \\ Department of Rheumatology, Rheumatism Research Wing, The Medical School, Birmingham, B15 2TJ United Kingdom
}

\begin{abstract}
When human IgG is exposed to free radical generating systems such as ultraviolet irradiation, peroxidizing lipids, or activated human neutrophils, characteristic auto-fluorescent monomeric and polymeric IgG is formed (excitation [Ex], $360 \mathrm{~nm}$, emission [Em], $454 \mathrm{~nm}) .1 \mathrm{~h}$ ultraviolet irradiation of IgG results in the following reductions in constituent amino acids; cysteine (37.0\%), tryptophan (17.0\%), tyrosine $(10.5 \%)$, and lysine $(3.6 \%)$. The fluorescent IgG complexes, when produced in vitro, can stimulate the release of superoxide from normal human neutrophils. In the presence of excess unaltered IgG, further fluorescent damage to IgG occurs. Measurement and isolation of fluorescent monomeric and polymeric IgG by high performance liquid chromatography, from in vitro systems and from fresh rheumatoid sera and synovial fluid, indicates that identical complexes are present in vivo; all these fluorescent complexes share the property of enhancing free radical production from neutrophils. The results described in this study support the hypothesis that fluorescent monomeric and aggregated IgG may be formed in vivo by oxygencentered free radicals derived from neutrophils, and that in rheumatoid inflammation this reaction may be self-perpetuating within the inflamed joint.
\end{abstract}

\section{Introduction}

Oxygen-centered free radicals (i.e. $\mathrm{O}_{\dot{2}}^{\overline{2}}$ and $\mathrm{OH}^{*}$ ) can be released by activated neutrophils in response to cell surface stimulation, by a variety of particulate and nonparticulate substances (1-5). Such highly reactive chemical species have the potential to denature proteins (6), oxidize lipids (7), damage DNA, and denature virtually all types of biomolecules $(8,9)$.

Ever since free radical reactions were first implicated in such processes, their relevance to the development of human pathological states has been sought (for review see reference 10). McCord and others $(11,12)$ have suggested that in rheumatoid inflammation, which is characterized by a large infiltration of phagocytic cells into the inflamed joint, neutrophils may release oxygen radicals into extracellular fluid and damage its macromolecular components. Such elements of the synovial fluid are normally unprotected by intracellular antioxidant enzymes such as superoxide dismutase (SOD), ${ }^{1}$ catalase, and glutathione peroxidase (11).

Address correspondence to Dr. J. Lunec, Department of Biochemistry, Selly Oak Hospital, Birmingham B29 6JD, United Kingdom. 1985.

Received for publication 18 October 1984 and in revised form 5 August

1. Abbreviations used in this paper: Em, emission; Ex, excitation; HPLC, high performance liquid chromatography; PMA, phorbol myristate acetate; SOD, superoxide dismutase.

J. Clin. Invest.

(c) The American Society for Clinical Investigation, Inc. 0021-9738/85/12/2084/07 \$1.00

Volume 76, December 1985, 2084-2090
We have shown previously that human IgG undergoes fluorescent and sulphhydryl-related damage when exposed to free radical reactions $(13,14)$. The fluorescence formation is thought to be related to selective hydroxylation and destruction of aromatic amino acid constituents of the protein $(15,16)$. In this report we have characterized the nature of the fluorescent changes in IgG that are induced by free radical reactions in vitro and identified similar fluorescent products in fresh human sera and synovial fluid, using high performance liquid chromatography (HPLC).

\section{Methods}

Chemicals. Human IgG (Cohn fraction II) phorbol myristate acetate (PMA), mannitol, thiourea, catalase, horse ferricytochrome $c$ and cytochalasin B were obtained from Sigma Chemical Co., St. Louis, MO. Protein molecular weight markers for chromatography were obtained from Pharmacia Fine Chemicals, Piscataway, NJ. Desferrioxamine was obtained from Ciba Geigy Corp., Pharmaceuticals Div., Summit, NJ. All other chemicals were of Analar grade and purchased from British Drug Houses Chemicals Ltd., Poole, Dorset, United Kingdom.

Fluorescence measurements. All fluorescence measurements were performed on an MPF-3L-spectrofluorimeter (Perkin Elmer Corp., Beaconsfield, Herts, United Kingdom). The instrument settings were as follows: excitation and emission slits, 12 and $14 \mathrm{~nm}$, respectively; sensitivity settings ranged from 1 to $30 \times$; wavelength calibration was performed with quinine sulfate ( $10 \mathrm{mmol} /$ liter in $100 \mathrm{mmol} /$ liter $\mathrm{H}_{2} \mathrm{SO}_{4}$ ); fluorescence intensity calibration was made with a polymer block standard (block 5 compound 610, Perkin-Elmer Corp., approximate concentration $5 \times 10^{-5} \mathrm{~mol} / \mathrm{liter}$ ). Filters of 310,190 , and $430 \mathrm{~nm}$ were used as appropriate and all measurements were made at ambient temperature.

Preparation of free radical altered $I g G$. In all experiments, human IgG was dissolved in $40 \mathrm{mmol} /$ liter phosphate buffer $\left(\mathrm{KH}_{2} \mathrm{PO}_{4} / \mathrm{K}_{2} \mathrm{HPO}_{4}\right)$, $\mathrm{pH} 7.4$, to give a concentration of $2.5 \mathrm{mg} / \mathrm{ml}$. 3- $\mathrm{ml}$ vol were irradiated (366- + 254-nm source) in matched quartz cuvettes, $1 \mathrm{~cm}^{2}$ in crosssection, or in open Petri dishes at a distance of $6 \mathrm{~cm}$ from the light source. Fluorescent alteration of IgG was also induced in separate experiments as follows: (a) $100 \mu \mathrm{l}$ of a mixture of copper sulfate $(0.5 \mathrm{mmol} /$ liter) plus hydrogen peroxide ( $100 \mathrm{mmol} / \mathrm{liter})$ was added to $3 \mathrm{ml}$ of $\mathrm{IgG}$ $(2.5 \mathrm{mg} / \mathrm{ml})$ and incubated at $25^{\circ} \mathrm{C}$ for $30 \mathrm{~min}$ (13). (b) Arachidonic acid was sonicated (Rapidus Ultrasonics, Shipley, Yorks, United Kingdom) in phosphate-saline buffer $\left(\mathrm{KH}_{2} \mathrm{PO}_{4} / \mathrm{K}_{2} \mathrm{HPO}_{4}, 40 \mathrm{mmol} /\right.$ liter; $\mathrm{NaCl}$

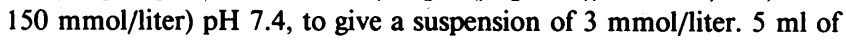
the suspension was then removed and added to an equal volume of 2.5 $\mathrm{mg} / \mathrm{ml} \mathrm{lgG}$ and incubated at $37^{\circ} \mathrm{C}$ for $1 \mathrm{~h}$.

Neutrophil experiments. Neutrophils were isolated from peripheral blood of healthy human volunteers by employing standard techniques of Ficol-Hypaque sedimentation and ammonium chloride lysis of erythrocytes. To induce free radical damage to IgG, neutrophils $(4 \mathrm{ml}$ of 4 $\times 10^{6}$ cells $/ \mathrm{ml}$ suspended in phosphate-buffered saline plus $2 \mathrm{mM}$ glucose) were incubated with an equal volume of $2.5 \mathrm{mg} / \mathrm{ml} \mathrm{IgG}$. Activation of cells was performed by adding PMA to a final concentration of $10 \mu \mathrm{g} /$ liter. Cells with and without PMA were then incubated with pure IgG for up to a period of $1 \mathrm{~h}$. In one series of experiments, the cells $(4 \mathrm{ml}$ of $4 \times 10^{6} \mathrm{cells} / \mathrm{ml}$ ) were incubated with $500 \mu \mathrm{l}$ of ultraviolet-altered $\mathrm{IgG}$ in the presence of excess unaltered $\operatorname{IgG}(4 \mathrm{ml}$ of $2.5 \mathrm{mg} / \mathrm{ml} \mathrm{IgG})$ at $37^{\circ} \mathrm{C}$ in order to test the hypothesis that free radical alteration of $\mathrm{IgG}$ might result in a perpetual production of fluorescent IgG mediated by the neutrophil. At various time periods, 200- $\mu$ l aliquots were removed, the cells were separated by centrifugation, and the supernatant assayed for fluorescence (Ex 360 nm, Em 454 nm). 
Neutrophil superoxide production. A continuous assay of superoxide generated by activated neutrophils was performed according to the method of Cohen and Chovaniec (17). Neutrophil suspensions (1 ml of $2 \times 10^{6} \mathrm{cells} / \mathrm{ml}$ ) were added to an equal volume of phosphate-buffered saline (40 mM KH $\mathrm{PO}_{4} / \mathrm{K}_{2} \mathrm{HPO}_{4} / 150 \mathrm{mM} \mathrm{NaCl} ; \mathrm{pH}$ 7.4) containing 2 $\mathrm{mM}$ glucose and $100 \mu \mathrm{M}$ ferricytochrome $c$. After time was allowed for temperature equilibration $\left(37^{\circ} \mathrm{C}\right), 500 \mu \mathrm{l}$ of the test IgG material (i.e., free radical altered IgG isolated by HPLC) was added.

A second identical solution, containing in addition $100 \mu \mathrm{g} / \mathrm{ml}$ of SOD, was also prepared. The mixture was placed in the blank compartment of a double beam spectrophotometer. In this way, continuous assay of superoxide-dependent cytochrome $c$ reduction could be monitored in the test sample at a constant temperature of $37^{\circ} \mathrm{C}$ for the duration of the reaction.

High performance liquid chromatography. Separation of samples of synovial fluids, sera, and IgG samples were performed on a TSK 3000 $\mathrm{SW}$ column. The proteins were eluted at $1 \mathrm{ml} / \mathrm{min}$ with phosphate buffer as mobile phase $\left(0.067 \mathrm{M} \mathrm{KH}_{2} \mathrm{PO}_{4}+0.1 \mathrm{M} \mathrm{KCl}\right)$. The elution of free radical altered IgG products was monitored with a fluorimeter (Gilson Instruments Ltd., Villiers le Bel, France). An o-pthaldehyde filter allowed detection of protein peaks with maximum excitation and emission of 360 and $454 \mathrm{~nm}$, respectively. Detection of proteins at $280 \mathrm{~nm}$ was also performed simultaneously using a Uvicord spectrophotometer (Pye Unicam).

Amino acid and carbohydrate analysis. A Locarte amino acid analyzer was used for the measurement of amino acids. Samples of IgG were hydrolyzed in sealed tubes at $6 \mathrm{M} \mathrm{HCl}$ at $110^{\circ} \mathrm{C}$ for $24 \mathrm{~h}$. Oxygen was removed from the sample by degassing. For tryptophan, which is entirely destroyed by acid hydrolysis, high yields were recovered from proteins by hydrolysis of protein in $4 \mathrm{M} \mathrm{Ba}(\mathrm{OH})_{2}$. The sample, at low $\mathrm{pH}$, was injected into a column of strong cation exchange resin by means of an automatic loader. The amino acids were then eluted from the column by a stepwise gradient of increasing $\mathrm{pH}$ and ionic strength. The column eluent was mixed with a stream of ninhydrin reagent, reacted at $100^{\circ} \mathrm{C}$, then detected at $570 \mathrm{~nm}$ ( $440 \mathrm{~nm}$ for proline). The amino acids were identified by their elution position and quantified by integration of the chromatogram.

Neutral sugars were separated by ion exchange chromatography of their borate complexes on a strong anion exchange resin. The mixture of sugars to be analyzed were obtained from IgG preparations after hydrolysis (as described above), and injected on the resin bed in a solution of $0.13 \mathrm{M}$ boric acid. A series of borate buffers of increasing $\mathrm{pH}$ and ionic strength then eluted the sugar-borate complexes. The sugars were visualized by mixing the eluent with a stream of orcinol/concentrated sulfuric acid reagent, heating at $95^{\circ} \mathrm{C}$ for $15 \mathrm{~min}$ followed by detection in a flow cell at $425 \mathrm{~nm}$ in a modified Jeol amino acid analyzer.

Clinical samples. Sera and synovial fluids were obtained for diagnostic or therapeutic purposes from patients (age range 27-85; mean 49) with classical or definite rheumatoid arthritis (according to American Rheumatism Association criteria) and from patients with other forms of arthritis (nonrheumatoid) presenting at the Department of Rheumatology, The Medical School. Normal control serum specimens were obtained from laboratory staff (age range: 35-60 yr; mean $43 \mathrm{yr}$ ).

For the purpose of the present study, synovial fluids were divided into two groups: (a) a nonrheumatoid series that was characterized mainly by clinical and/or radiological evidence of degenerative arthritic lesions, but also included three fluids from patients with inflammatory (one ankylosing spondylitis, two psoriatic arthritis) seronegative arthritis; (b) a rheumatoid group classified according to American Rheumatism Association criteria. No attempt was made to score the activity of the disease at the time of sampling. All patients were receiving conventional analgesic/ anti-inflammatory therapy.

Statistical methods. The statistical analysis of significance for paired data was performed using a $t$ test.

\section{Results}

Changes in the physical and chemical nature of IgG induced by free radicals. When human IgG was exposed to ultraviolet ir- radiation, the protein became characteristically fluorescent (excitation [Ex] $366 \mathrm{~nm}$, emission [Em] $454 \mathrm{~nm}$ ) and aggregated. Fig. 1 describes the molecular weight and interrelationship of fluorescent IgG protein complexes produced by irradiating IgG for up to $60 \mathrm{~min}$. The fluorescence (Ex $360 \mathrm{~nm}, \mathrm{Em} 454 \mathrm{~nm}$ ) and ultraviolet $(280 \mathrm{~nm})$ elution profiles in this figure describe the successive production of fluorescent monomeric IgG, intermediate aggregates (dimers), and high molecular weight polymers $\left(>10^{6}\right.$ [one million] mol wt) as identified by HPLC. After 90 min ultraviolet irradiation, fluorescent monomer formation plateaued, while fluorescent aggregates continued to rise. Low molecular weight fragments consistent with production of heavy and light chains of IgG rather than proteolytic fragments could also be distinguished at higher monitor sensitivities. The relative changes in the proportion of amino acids, measured in IgG over this time period, are illustrated in Fig. 2. The amino acids found most susceptible to free radical attack were cysteine, tryptophan, tyrosine, and lysine; reduction of these amino acids after a total

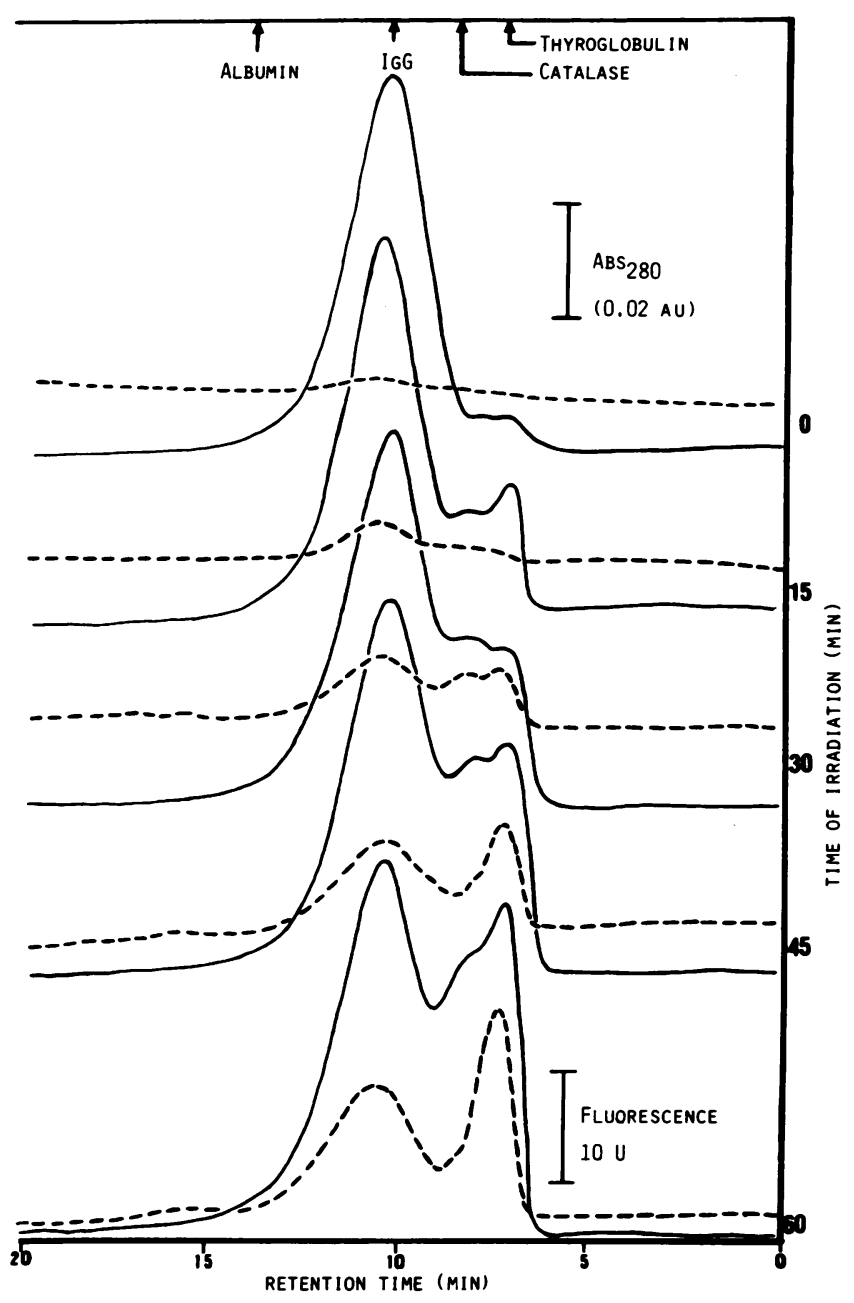

Figure 1. Time relationship between fluorescent monomeric and polymeric free radical reaction products of human IgG during timed intervals of exposure of IgG to ultraviolet light (366- + 254-nm source). Elution of IgG products was monitored simultaneously for absorbance at $280 \mathrm{~nm}(-)$ and fluorescence (--.--; Ex $360 \mathrm{~nm}$, Em $454 \mathrm{~nm})$. The fluorescence detector was set at range 20X: the maximum setting available was $100 \times$. Molecular weight calibration of the TSK 3000 column was performed by monitoring the elution time of pure standards of albumin $(60,000 \mathrm{~mol} \mathrm{wt}), \operatorname{IgG}(150,000 \mathrm{~mol} \mathrm{wt})$, catalase $(230,000 \mathrm{~mol} \mathrm{wt})$, and thyroglobulin $(600,000 \mathrm{~mol} \mathrm{wt})$. 


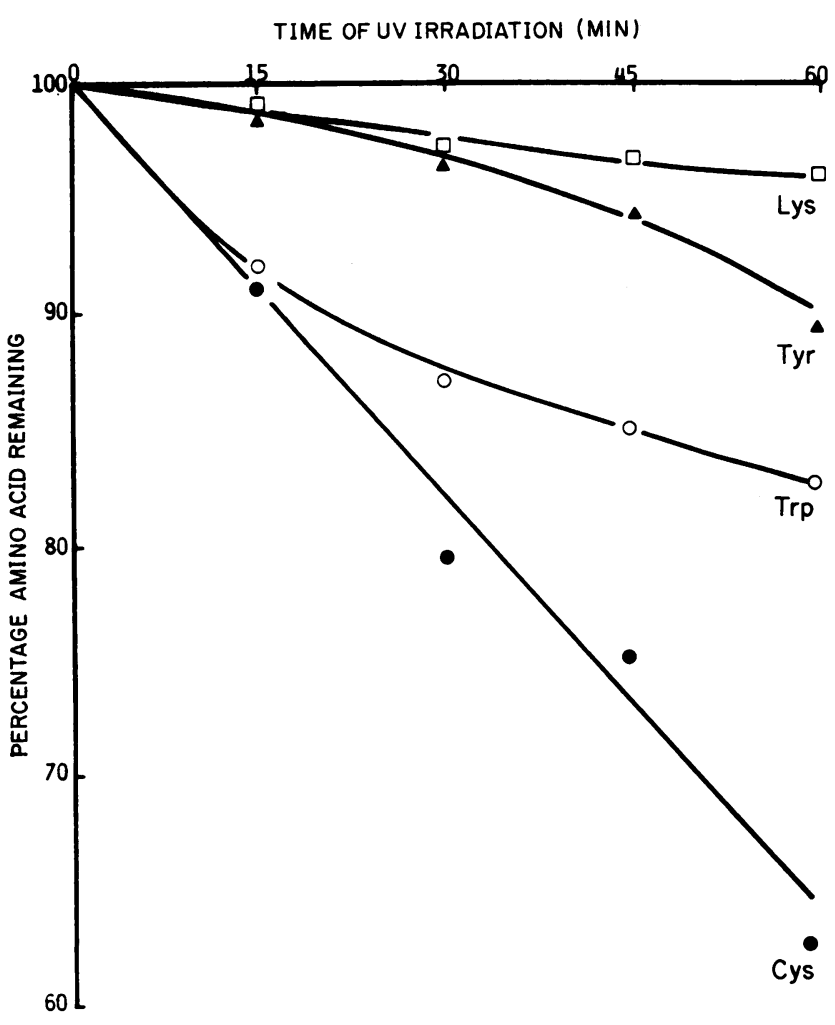

Figure 2. Relative changes in the cysteine (๑), tryptophan (o), tyrosine $(\Lambda)$, and lysine ( $\square$ ) content of human IgG following ultraviolet irradiation (Results represent the mean of duplicate analyses.). All other amino acids were not significantly altered over the 60 -min duration of ultraviolet irradiation.

of $1 \mathrm{~h}$ ultraviolet irradiation of $\mathrm{IgG}$ was calculated as 37.0, 17.0, 10.5 , and $3.6 \%$, respectively.

Self-perpetuation of fluorescent alteration to IgG. Fig. 3 illustrates the relationship between time of irradiation and fluorescent IgG production in the supernatant from activated neutrophils. The results show that irradiation of IgG generates two optima for inducing the further production of fluorescent IgG by activated neutrophils; one after $15 \mathrm{~min}$ irradiation of IgG, corresponding to very little aggregate formation, and one at 60 min of irradiation that represented predominantly aggregates of the molecule that had molecular weights in excess of $10^{6}$. In a matched series of experiments (Fig. 4), normal human neutrophils were incubated with IgG that had been exposed to identical time periods of ultraviolet radiation. Superoxide-dependent cytochrome $c$ reduction was measured during its incubation with irradiated IgG and cells. Production of superoxide by these neutrophils in response to stimulation by IgG reached a maximum after $\sim 45 \mathrm{~min}$ of irradiation. Cells that had been preincubated with the fungal metabolite cytochalasin $B$, to inhibit vacuole formation, increased their ability to generate superoxide in the presence of free radical altered IgG. This was consistently the case throughout the 90 -min period of irradiation, although superoxide production from these cells correlated best with altered fluorescent monomer activity.

In PMA-stimulated neutrophils incubated with native IgG (Table I), subsequent fluorescent IgG formation could be inhibited by SOD $(9.5 \%)$, catalase $(71.0 \%)$, thiourea $(20 \%)$, desferrioxamine $(32.8 \%)$, and mannitol $(4.7 \%)$. Catalase was by far the most effective at inhibiting fluorescence formation.

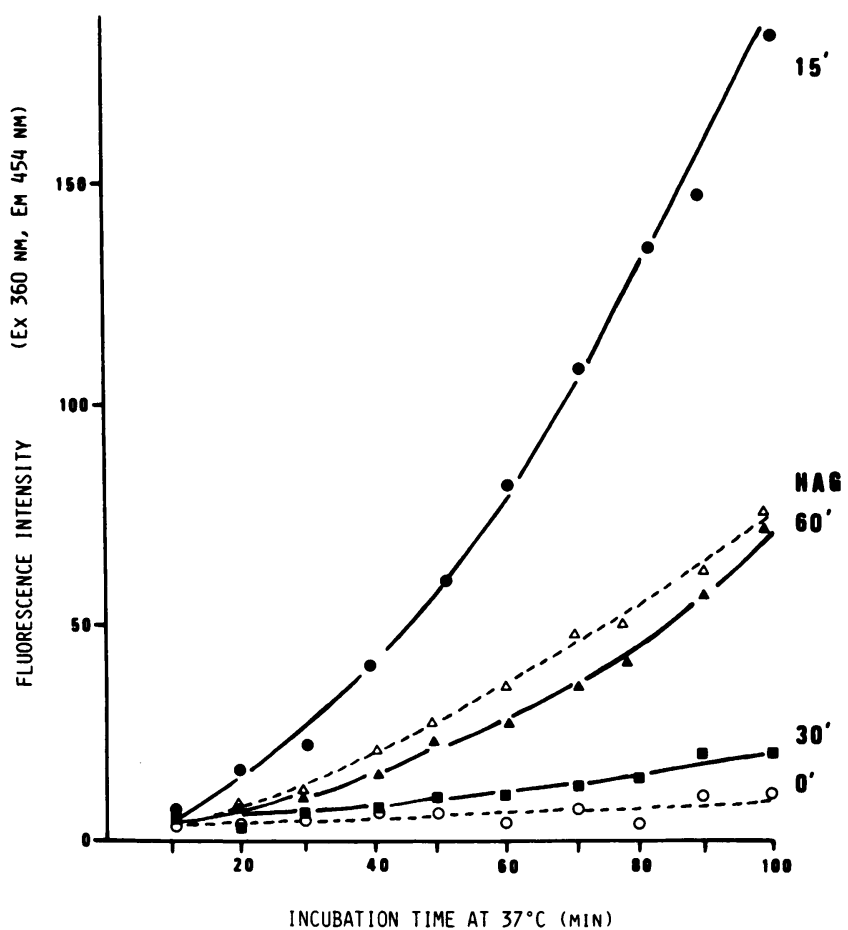

Figure 3. Generation of fluorescent IgG (Ex $360 \mathrm{~nm}$, Em $454 \mathrm{~nm}$ ) by human neutrophils $\left(2.0 \times 10^{6}\right.$ cells $/ \mathrm{ml}$ phosphate-buffered saline) incubated at $37^{\circ} \mathrm{C}$ with normal human IgG that had been irradiated with ultraviolet light $(366+254 \mathrm{~nm}$ ) for $0 \mathrm{~min}(0), 15 \mathrm{~min}(\bullet), 30$ $\min (\bullet)$, and $60 \mathrm{~min}(\Delta)$ in the presence of excess unaltered human IgG (final concentration $2.5 \mathrm{mg} / \mathrm{ml}$ ). Heat-aggregated IgG (15 mins, $63^{\circ} \mathrm{C}$ ) is shown for comparison $(\Delta)$. The fluorescence changes represent fluorescence increases over control values (i.e., identical system incubated without cells). The results are expressed as the mean of four separate experiments.

Measurement and isolation of free radical altered $\operatorname{IgG}$ by $H P L C$. Fig. 5 compares the fluorescence HPLC elution profile of free radical altered IgG with typical samples of rheumatoid sera and synovial fluids. Both fluids and sera had significant fluorescence associated with the IgG fraction. This encouraged us to look at a small series of 10 nonrheumatoid and 10 rheumatoid synovial fluids (Table II). Rheumatoid synovial fluids were found generally to have significantly more fluorescence associated with IgG than nonrheumatoid fluids. This was also the case in rheumatoid sera vs. control sera. In both instances this fluorescence remained significantly increased even after correction for IgG concentration. Fluorescent complexes that were indistinguishable by HPLC from those generated by free radical reactions were isolated from both rheumatoid sera and synovial fluid. In order to see whether these individual fractions further resembled in vitro generated products, they were tested for their ability to stimulate neutrophils to generate the superoxide radical. Table III shows the relative activities of fractions separated and isolated by HPLC. Heat-aggregated IgG had lower activity than IgG that had been irradiated, mixed with peroxidizing lipid, or reacted with a copper-hydrogen peroxide mixture. Whole rheumatoid sera and synovial fluids were also able to stimulate neutrophils to generate superoxide; however, the total activities of the fluid and sera were consistently of the order of $50 \%$ of the activity of some of the individual monomeric fluorescent protein fractions isolated by HPLC. 


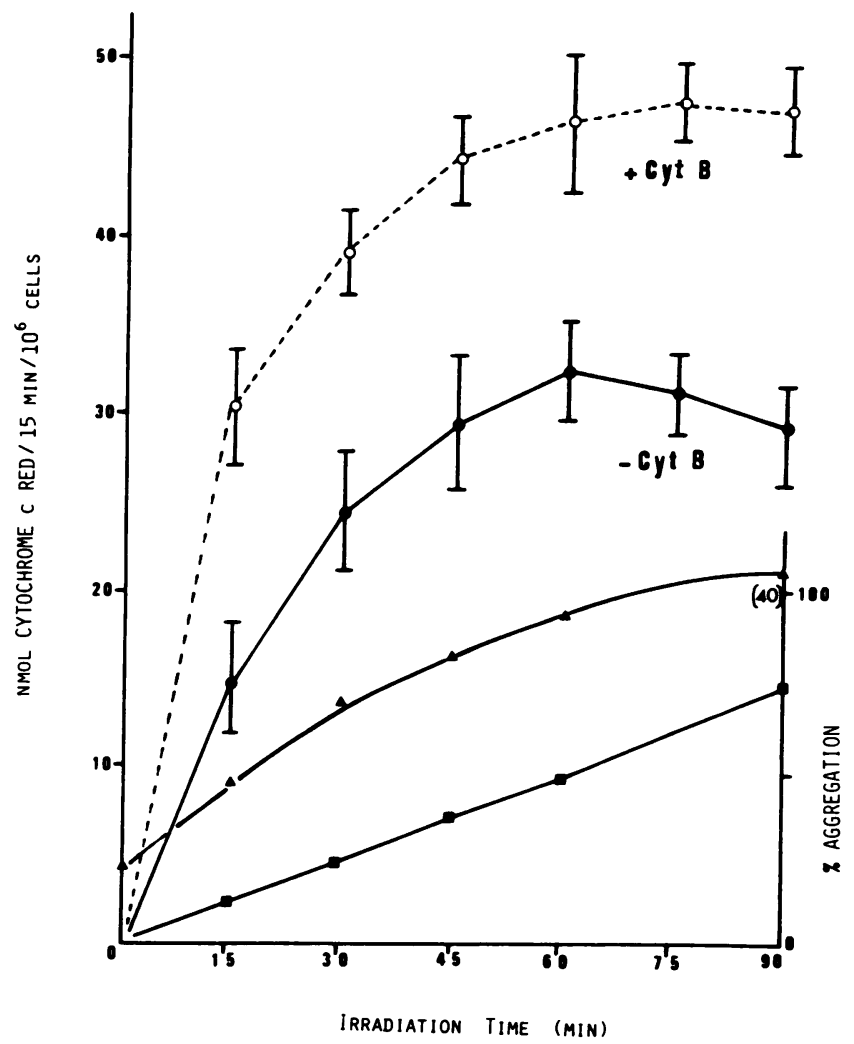

Figure 4. Superoxide $\left(\mathrm{O}_{\bar{i}}^{\overline{1}}\right)$ production by human neutrophils activated by IgG that had been ultraviolet irradiated for various time intervals, with (0) and without $(\bullet)$ preincubation with cytochalasin B. Results are \pm SEM of 10 experiments. A correlation with the production fluorescent monomer $(\boldsymbol{\Delta})$ and aggregates $(\boldsymbol{\omega})$ is also shown. Fluorescence scale is shown in parenthesis. Percentage aggregation was determined by calculation of the ratio of aggregate peak (eluting within the void volume $[500,000 \mathrm{~mol} \mathrm{wt}]$ to the ultraviolet absorbance $[280 \mathrm{~nm}]$ ) of untreated monomeric IgG.

\section{Discussion}

Previously we have reported that fluorescence (Ex $360 \mathrm{~nm}, \mathrm{Em}$ $454 \mathrm{~nm}$ ) and aggregation, which accompanies free radical damage to IgG, occurs at the site of the aromatic amino acids on the IgG molecule as well as at the surface intramolecular disulfide bonds (14). In this report we confirm and extend these findings,

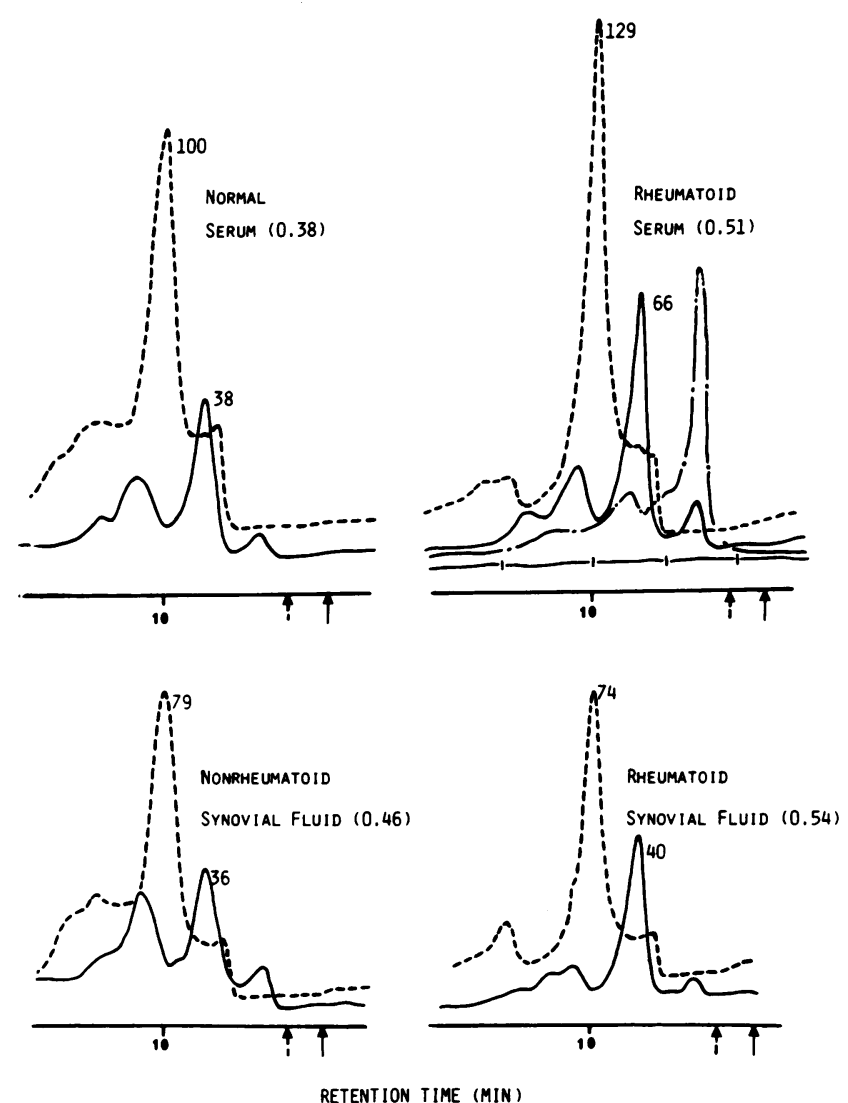

Figure 5. A comparison of the HPLC profiles of rheumatoid synovial fluid, corresponding serum, nonrheumatoid fluid, and normal serum. Fluorescence of ultraviolet irradiated IgG (-•-) and heat-aggregated $\operatorname{IgG}(-1-)$ are shown for comparison. Sera and synovial fluids were diluted with mobile phase before injection onto a TSK $3000 \mathrm{SW}$ column and eluted at $1.0 \mathrm{ml} / \mathrm{min}$ with buffer $\left(0.067 \mathrm{M} \mathrm{KH}_{2} \mathrm{PO}_{4}+0.1 \mathrm{M}\right.$ $\mathrm{KCl}$; pH 6.8). Fluorescence monitoring (-) of eluent was carried out at $450-460 \mathrm{~nm}$ and ultraviolet monitoring (-.-.-) at $280 \mathrm{~nm}$. Fluorescence and ultraviolet intensity measurements are indicated at the top of IgG peaks. The corresponding fluorescence-ultraviolet ratios are shown in parenthesis. $\uparrow$ Indicates injection point. Ultraviolet profiles are displaced by 2 min for the sake of clarity.

and show that the thiol containing amino acid cysteine is the most susceptible to free radical attack. This is consistent with the oxygen radical-dependent reduction and breaking of disulfide

Table I. Fluorescence Generation in Native IgG Caused by PMA Activation of Neutrophils

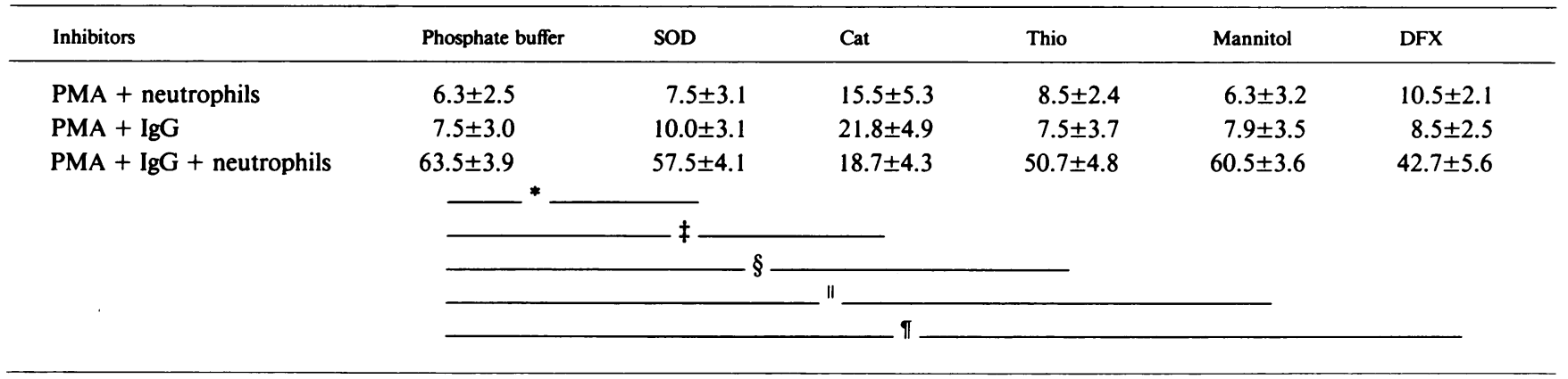

Fluorescence intensity measurements were made on supernatants after $1 \mathrm{~h}$ incubation of IgG with neutrophils (Ex $360 \mathrm{~nm}$, Em $454 \mathrm{~nm}$ ). In parallel experiments, netrophils were preincubated with inhibitors plus PMA before addition of IgG. The final concentrations of each inhibitor were as follows: SOD, $100 \mu \mathrm{g} / \mathrm{ml}$; catalase, $500 \mu \mathrm{g} / \mathrm{ml}$; thiourea, $50 \mathrm{mmol} /$ liter; mannitol, $50 \mathrm{mmol} /$ liter, and desferroximine (DFX), $0.5 \mathrm{mmol} /$ liter. The results are expressed as the mean $\pm 1 \mathrm{SD}$ of four separate experiments. $\quad * P<0.05 . \quad \ddagger P \ll 0.001 . \quad \S P<0.001$. "NS. II $P \ll 0.001$. 
Table II. Fluorescent (FL) Monomeric IgG in Normal Sera, Rheumatoid Sera, and Matched Synovial Fluids (SF)

\begin{tabular}{lllll}
\hline & $\begin{array}{l}\text { SF (nonrheumatoid) } \\
(n=10)\end{array}$ & $\begin{array}{l}\text { SF (rheumatoid arthritis) } \\
(n=10)\end{array}$ & $\begin{array}{l}\text { Rheumatoid sera } \\
(n=10)\end{array}$ & $\begin{array}{l}\text { Normal sera } \\
(n=15)\end{array}$ \\
\hline Fl & $13.1 \pm 8.3^{*}$ & $25.4 \pm 6.2$ & $47.1 \pm 38.8^{*}$ & $21.4 \pm 10.6$ \\
Ultraviolet & $29.2 \pm 19.1$ & $39.0 \pm 10.4$ & $97.8 \pm 33.9$ & $56.4 \pm 8.9$ \\
Fl/ultraviolet & $0.46 \pm 0.26 \ddagger$ & $0.52 \pm 0.15$ & $0.49 \pm 0.36 \ddagger$ & $0.38 \pm 0.11$ \\
\end{tabular}

Samples were diluted $1 / 20$ with mobile phase, and $500 \mu \mathrm{l}$ of this was injected onto a TSK 3000 column. The mobile phase used for elution of fluorescent IgG was $0.67 \mathrm{M} \mathrm{KH}_{2} \mathrm{PO}_{4}+0.1 \mathrm{M} \mathrm{KCl}$. Ultraviolet monitoring of eluent was at $280 \mathrm{~nm}$, and fluorescence monitoring was at $454 \mathrm{~nm}$ when excited at $360 \mathrm{~nm}$. The fluorescence of the monomeric $\mathrm{IgG}$ was expressed as a ratio of fluorescence to its ultraviolet absorbance (280 $\mathrm{nm}$ ) so as to take into account variability in the IgG content of the samples. ${ }^{*} P<0.001 . \quad \ddagger P<0.01$.

bonds and the formation of thiol groups (13). The reductions that we observe in the aromatic amino acids tryptophan and tyrosine are in agreement with our previous findings that aromatic amino acids, in particular tryptophan and tyrosine, undergo fluorescence formation when they are irradiated independently of the protein molecule $(15,16)$. Several of the major fluorescent oxidation products of tryptophan, which have been generated by free radical reactions, have been tentatively identified, and their structures are shown in Fig. 6. The oxidized derivatives of tryptophan are shown as they might occur in the free radical altered IgG molecule. The structures of the main components of the free radical action on tryptophan include a fluorescent hydroxylated derivative (5-hydroxy tryptophan); compounds that result from the bond breaking of the pyrrole structure of tryptophan are also found. The hydroxylation of tryptophan residues on IgG is consistent with our experimental findings since $(a)$ hydroxyl radicals are produced by human neutrophils when they are metabolically activated, $(18)$, and $(b)$ the fluorescent generation of fluorescent IgG can be inhibited by

Table III. Superoxide Production from Neutrophils after Stimulation with Fractions of Fluorescent IgG Isolated by HPLC

\begin{tabular}{lll}
\hline Fraction & Origin & nmol $\mathrm{O}_{\mathbf{z}}^{\overline{2}} / 15 \mathrm{~min} / 10^{6}$ cells \\
\hline & Total serum & 0.85 \\
Fluorescent monomer & & 1.85 \\
Fluorescent aggregate & & 0.50 \\
& Total synovial fluid & 1.30 \\
Fluorescent monomer & & 2.75 \\
Fluorescent aggregate & & 1.70 \\
& IgG/Cu/ $\mathrm{H}_{2} \mathrm{O}_{2}$ & 1.25 \\
& $\mathrm{PAG}$ mixture & 0.60 \\
& $\mathrm{HAG}$ mixture & 0.35 \\
& Human IgG & 0.10 \\
& Human IgG $\left(15^{\prime} \mathrm{UV}\right)$ & 0.95 \\
Fluorescent monomer & & 0.85 \\
Fluorescent aggregate & & 0.30
\end{tabular}

Total IgG concentrations of fractions were standardized at $\sim 2.5 \mathrm{mg} / \mathrm{ml}$ when samples were added $(200 \mu \mathrm{l})$ to $2 \mathrm{ml}$ of a suspension of normal human neutrophils (final cell concentration $1 \times 10^{6}$ \% $\mathrm{ml})$. Superoxide production was calculated using the following extinction coefficient for reduced cytochrome $c: 21.1 \times 10^{3} \mathrm{~m}^{-1} \mathrm{~cm}^{-1}$. These results are the mean of four separate experiments. PAG is a peroxidized arachidonic acid IgG mixture; HAG is heat aggregated IgG $\left(63^{\circ} \mathrm{C}, 15 \mathrm{~min}\right)$. UV, ultra-violet irradiation.

desferrioxamine, catalase and hydroxyl radical scavengers. (In our experiments, mannitol was less effective than thiourea, probably because of its relatively low reactivity with hydroxyl radical.) Further support for this mechanism of damage comes from the fact that the hydroxylation of aromatic compounds is an established procedure for the detection and measurement of the hydroxyl free radical (19).

We believe that fluorescence formation (Ex 360 nm, Em 454 $\mathrm{nm})$ specifically characterizes free radical-induced damage to proteins. This is also implied by other workers (20) who have observed identical visible fluorescence changes occurring in a variety of proteins when they have been stored or artificially aged. The fluorescence alteration (Ex $360 \mathrm{~nm}, \operatorname{Em~} 454 \mathrm{~nm}$ ) is therefore not specific to IgG, but generally can reflect free radical (in particular hydroxyl-free radical) damage to any protein. The extent of the fluorescent damage would seem to be related to the periodicity and content of aromatic amino acids within the protein.
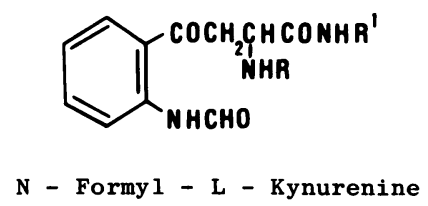<smiles>NC(=O)Nc1c[nH]c2ccc(O)cc12</smiles>

5 - Hydroxy Tryptophan<smiles>Nc1ccccc1C(=O)CNC(=O)O</smiles>

Kynurenine<smiles>[R]NC(C=O)Cc1c[nH]c2ccccc12</smiles>

Tryptophan
Figure 6. A structural comparison of the main products of the free radical oxidation of tryptophan. NHR and (CONHR $\left.{ }^{1}\right)$ represent positions of peptide link. 
It appears likely that the lysis of surface disulfide bonds alone can result in a significant conformational change in the IgG molecule; however, hydroxylation and damage to the aromatic amino acids may also give rise to specific areas of damage in the protein that cause it to polymerize. Alteration in amino acid structure is considered an important prerequisite for the formation of IgG aggregates and the subsequent production of rheumatoid factors (21). This mechanism of aggregation is supported by our own results, since the relationship and distribution of fluorescence between the monomeric, intermediate, and polymeric forms of IgG suggest that a critical concentration of altered monomer fluorescence is required for the subsequent polymerization of the molecule. This situation contrasts with the widely used heat aggregation model $\left(63^{\circ} \mathrm{C}, 15 \mathrm{~min}\right)$, which often, but not always reproducibly, results in the generation of dimers and polymers, neither of which are fluorescent.

The activation of neutrophils by polymeric IgG was anticipated, as similar results have also been described for heat-aggregated IgG. However, we were surprised to find that free radical denatured monomeric IgG activated neutrophils to generate superoxide. There appears to be no apparent specificity in the mode of induction of the respiratory burst in neutrophils, since several different substances can interact and perturb the plasma membrane. We would suggest that, in the case of our altered monomeric IgG, the binding to the cell occurs probably through Fc receptors on the cell surface. For this to happen efficiently, the molecule of IgG needs to denature or unfold. Aggregation could enhance this reaction, at least until either the aggregation is such as to conformationally restrict Fc binding, or, cause saturation of receptors that in turn reduces the availability of the receptor as a trigger for free radical production. Either mechanism would explain the eventual falloff in $\mathrm{O}_{\overline{2}}$ production from neutrophils as aggregation of IgG progresses with increased ultraviolet exposure.

In rheumatoid disease it appears that there is little if any inherent difference between the ability of rheumatoid neutrophils to generate free radicals compared with normal control neutrophils $(22,23)$. However, recently Gale and his co-workers (24) have observed that rheumatoid sera and synovial fluids can stimulate neutrophils to generate oxygen-centered free radicals. They have also shown that this is a function of the immune complexes present. IgG aggregation is thought to be a stimulus for the formation of immune complexes with rheumatoid factor antibody $(25,26)$. These complexes are thought to be important in amplifying and perpetuating rheumatoid inflammation (27). For several years now, physical and chemical methods for denaturing IgG have served as models for the observed alteration of IgG found in rheumatoid sera and synovial fluid (26); however, heat aggregation of $\mathrm{IgG}$ has never been convincingly related to biochemical or pathological mechanisms occurring in the rheumatoid joint. In this paper we have shown that neutrophils, activated during inflammation, have the potential to alter IgG so that it becomes fluorescent and aggregates. Alternative means of generating free radicals also results in identical conformational changes to IgG. Recently other workers have shown that hydrogen peroxide can aggregate IgG via the myeloperoxidase-hydrogen peroxide system (28), but only in the presence of catechol or orthoquinone. We and others $(13,29)$ have shown previously that hydrogen peroxide, together with cupric salts or catalytic iron, will promote fluorescence formation and aggregation that can be inhibited in vitro by hydroxyl radical scavengers and metal chelators such as desferrioxamine. This is presumably due to the following generalized Fenton reaction that could occur within synovial fluid. $\mathrm{M}^{n+}+\mathrm{H}_{2} \mathrm{O}_{2} \rightarrow \mathrm{M}^{(n+1)+}+\mathrm{OH}^{\bullet}+\mathrm{OH}^{-}$. In support of this mechanism, Gutteridge et al. (30) have described the presence of a form of iron in synovial fluid that could act as a catalyst for this reaction.

In this report we have distinguished other proteins by HPLC, apart from IgG, which are also fluorescent when isolated from biological material. We suggest that these fluorescent proteins (approximate Ex $360 \mathrm{~nm}, \mathrm{Em} 460 \mathrm{~nm}$ ) isolated from sera and synovial fluid, also reflect the extent of free radical reactions induced by polymorphonuclear leukocytes during chronic inflammation. Although the changes initiated in other as yet uncharacterized proteins in human sera and synovial fluid may also be of importance in the pathogenesis of rheumatoid inflammation, we have studied here mainly the possible implications of altering the IgG, because its free radical denaturation may be the key to the production of rheumatoid factors in rheumatoid arthritis.

We have demonstrated that fluorescent monomer and aggregates are present in synovial fluid and sera, and have found a significant difference between the fluorescence to ultraviolet ratios of monomer in nonrheumatoid vs. rheumatoid fluids despite the fact that $(a)$ some of the nonrheumatoid fluids were taken from patients diagnosed as having an inflammatory arthropathy, and $(b)$ no account was taken of whether the disease was in remission or active at the time of sampling.

Although we have shown that catalase is by far the most potent at inhibiting fluorescence damage to $\mathrm{IgG}, \mathrm{H}_{2} \mathrm{O}_{2}$ itself is known not to be damaging (at these concentrations) unless it is reacting in the presence of catalytic amounts of transition metal ions (30). We would therefore suggest hydroxyl (generated by a Fenton reaction)-mediated damage to IgG as a cause of its aggregation in vivo. The inhibition by the iron chelator desferrioxamine strongly supports this conclusion. IgG complexes produced by free radical reactions are fluorescent and can activate resting neutrophils to produce further free radicals. When cytochalasin B is added to neutrophils, fluorescent IgG aggregates may still engage appropriate receptors, but they are not endocytosed. It appears, therefore, from our results, that free radical altered IgG potentially can stimulate neutrophils to generate further free radicals by a process that is, at least in part, independent of phagocytosis. Similar results have also been obtained by workers using the heat aggregation model (31-33).

Finally, perhaps the most important implication of this work is that free radical damage to IgG could be perpetuated, provided that there is a suitable supply of substrate IgG at the site of inflammation. This is certainly the case in rheumatoid synovial fluid, where up to $50 \mathrm{mg}$ of IgG can be synthesized per day (34). From our HPLC and in vitro studies, we would suggest that fluorescent monomeric and aggregated IgG present in synovial fluid can activate human neutrophils in an identical manner to their in vitro-generated counterparts. Taken together, these observations may be of considerable importance, since they describe a possible self-perpetuating mechanism of free radical release and tissue damage mediated by the neutrophil. Conversion of complement by free radical altered IgG might further amplify this destructive mechanism, which would be consistent with findings of complement activation and depletion in rheumatoid sera and synovial fluid (35).

\section{Acknowledgments}

We would like to thank Ciba Geigy Pharmaceuticals, the Arthritis and Rheumatism Council, and the West Midlands Regional Health Authority for their financial support. 


\section{References}

1. Babior, B. H., R. S. Kipnes, and J. T. Cumutte. 1973. Biological defense mechanisms. The production by leukocytes of superoxide a potential bacteriacidal agent. J. Clin. Invest. 52:741-744.

2. Salin, M. L., and J. M. McCord. 1975. Free radicals and inflammation. J. Clin. Invest. 56:1319-1323.

3. Tauber, A. I., T. G. Gabig, and B. H. Babior. 1979. Evidence for production of oxidising radicals by the particulate $\mathrm{O}_{2}^{-}$-forming system from human neutrophils. Blood. 53:666-676.

4. Takanaka, K., and P. J. O'Brien. 1980. Generation of activated oxygen species by polymorphonuclear leukocytes. FEBS (Fed. Eur. Biochem. Soc.) Lett. 110:283-286.

5. Weiss, S. J., P. K. Rustagi, and A. F. LoBuglio. 1978. Human granulocyte generation of hydroxyl radical. J. Exp. Med. 147:316-323.

6. Henriksen, T., T. B. Melo, and G. Saxebol. 1976. Free radical formation in proteins and protection from radiation damage. In Free Radicals in Biology, Vol. II. W. A. Pryor, editor. Academic Press, Inc., NY. 213-256.

7. Petrone, W. F., D. K. English, K. Wong, and J. McCord. 1980. Free radicals and inflammation in superoxide dependent activation of a neutrophil chemotactic factor in plasma. Proc. Natl. Acad. Sci. USA. 77:1159-1163.

8. Henriksen, T., R. Bergene, A. Heiber, and E. Sagstuen. 1976. Radical reactions in nucleic acids: crystal systems. In Free Radicals in Biology, Vol. II. W. A. Pryor, editor. Academic Press, Inc., NY. 257294.

9. Borg, D. C., K. M. Schaich, J. J. Elmore, and J. A. Bell. 1978. Cytotoxic reactions of free radical species of oxygen. Photochem. Photobiol. 28:887-907.

10. Pryor, W. A. 1978. The formation of free radicals and the consequences of their reactions in vivo. Photochem. Photobiol. 28:787-801.

11. McCord, J. M. 1974. Free radicals and inflammation: protection of synovial fluid by superoxide dismutase. Science (Wash. DC). 185: 529-530.

12. Fantone, J. C., and P: A. Ward. 1982. Role of oxygen-derived free radicals and metabolites in leukocyte dependent inflammatory reactions. Am. J. Pathol. 107:397-418.

13. Wickens, D. G., A. G. Norden, J. Lunec, and T. L. Dormandy. 1983. Fluorescence changes in human gamma globulin induced by free radical activity. Biochim. Biophys. Acta. 742:607-616.

14. Wickens, D. G., T. L. Graff, J. Lunec, and T. L. Dormandy. 1981. Free radical mediated aggregation of human gamma globulin. Agents Actions. 11:6-7.

15. Roshchupkin, D. I., V. V. Talitsky, and A. B. Pelenisyn. 1979. Fluorimetric study of tryptophan photolysis. Photochem. Photobiol. 30: 635-643.

16. Sun, M., and S. Zigman. 1978. Isolation and identification of tryptophan photoproducts from aqueous solutions of tryptophan exposed to near UV light. Photochem. Photobiol. 29:893-897.

17. Cohen, H. J., and M. A. Chovaniec. 1978. Superoxide generation by digitonin-stimulated guinea pig granulocytes. J. Clin. Invest. 61:10811096.

18. Repine, J. E., J. W. Eaton, M. W. Anders, J. R. Hoidal, and
R. B. Fox. 1979. Generation of hydroxyl radical by enzymes, chemicals, and human phagocytes in vitro. J. Clin. Invest. 64:1642-1651.

19. Richmond, R., B. Halliwell, J. Chauhan, and A. Darbre. 1981. Superoxide dependent formation of hydroxyl radicals: detection of hydroxyl radicals by the hydroxylation of aromatic compounds. Anal. Biochem. 118:328-335.

20. Avigliano, L., Sirianni, P. L. Morpurgo, and A. Finazz-Agro. 1983. Copper is not responsible for the fluorescence of blue oxides. FEBS (Fed. Eur. Biochem. Soc.) Lett. 163:274-276.

21. Johnson, P. M., S. J. Watkins, and E. T. Holborrow. 1975. Anti globulin production to altered IgG in rheumatoid arthritis. Lancet. I: 611-613.

22. Kay, N. E., and S. D. Douglas. 1979. Monocyte metabolic activation in patients with rheumatoid arthritis. Proc. Soc. Exp. Biol. Med. 161:303-306.

23. James, D. W., W. H. Betts, and L. Cleland. 1983. Chemiluminescence of polymorphonuclear leukocytes from rheumatoid joints. $J$. Rheumatol. 10:184-189.

24. Gale; R., J. V. Bertouch, J. Bradley, and P. J. Roberts-Thompson. 1983. Direct activation of neutrophil chemiluminescence by rheumatoid sera and synovial fluid. Ann. Rheum. Dis. 42:158-162.

25. Munthe, E., and J. B. Natvig. 1971. Characterisiation of IgG complexes in eluates from rheumatoid tissue. Clin. Exp. Immunol. 8: 249-262.

26. Hannestad, K. 1967. The presence of aggregated gamma globulin in certain rheumatoid synovial effusions. Clin. Exp. Immunol. 2:511529.

27. Carter, P. M. 1973. Occasional survey: immune complex diseases. Ann. Rheum. Dis. 32:265-271.

28. Jasin, H. E. 1983. Generation of IgG aggregates by the myeloperoxidase-hydrogen peroxide system. J. Immunol. 130:1918-1923.

29. Gutteridge, J. M. C., and S. Wilkins. 1983. Copper salt-dependent hydroxyl radical formation. Damage to proteins acting as antioxidants. Biochim. Biophys. Acta. 759:38-41.

30. Gutteridge, J. M. C., D. A. Rowley, and B. Halliwell. 1982. Superoxide dependent formation of hydroxyl radicals in the presence of iron salts. Detection of catalytic iron and antioxidant activity in body fluids. Biochem. J. 206:605-609.

31. Weiss, S. J., and P. A. Ward. 1982. Immune complex induced generation of oxygen metabolites by human neutrophils. J. Immunol. 129:309-313.

32. Goldstein, I. M., D. Roos, H. B. Kaplan, and G. Weissman. 1975. Complement and immunoglobulins stimulate superoxide production by human leukocytes independently of phagocytosis. J. Clin. Invest. 156:1155-1163.

33. Johnston, R. B., and J. E. Lehmeyer. 1976. Elaboration of toxic oxygen byproducts by neutrophils in model of immune complex disease. J. Clin. Invest. 57:836-841.

34. Sliwinski, A. J., and N. J. Zvaifler. 1970. In vivo synthesis of IgG in rheumatoid synovium. J. Lab. Clin. Med. 76:304-310.

35. March, R. E., J. S. Reeback, E. J. Holborrow, V. E. Jones, and R. K. Jacoby. 1982. The complement fixing properties and class distribution of rheumatoid factors (antiglobulins) in rheumatoid arthritis and other diseases. Clin. Exp. Immunol. 48:555-560. 